\title{
A technique for advancing an endotracheal tube over a stylet during intubation when an assistant is not available
}

\author{
Qiusheng Ren, MD $\cdot$ Lei Li, MD · Wanjun Yu, MD
}

Received: 9 March 2016/Revised: 11 March 2016/ Accepted: 22 March 2016/Published online: 30 March 2016

(c) Canadian Anesthesiologists' Society 2016

\section{To the Editor,}

Tracheal intubation plays a well-established role in airway management, and a stylet is frequently used to facilitate passage of the endotracheal tube (ETT). Usually, an experienced assistant removes the stylet by holding it firmly while withdrawing it as the ETT is advanced into the trachea. Thus, not having an assistant available presents a challenge, requiring modification of the usual intubation procedure.

We describe a technique for withdrawing the stylet when no assistant is available (video available as Electronic Supplementary Material). After inserting the laryngoscope, its position and lifting force are adjusted to optimize the glottis view. After guiding the ETT mounted on the stylet between the vocal cords, the operator grasps the ETT between the thumb and forefinger of the left hand (which is also holding the laryngoscope). The right hand
Electronic supplementary material The online version of this article (doi:10.1007/s12630-016-0636-8) contains supplementary material, which is available to authorized users.

\section{Q. Ren, MD $(\bowtie) \cdot$ L. Li, MD}

Department of Anesthesia, Yinzhou People's Hospital, Ningbo University Medical College, Ningbo, Zhejiang, China

e-mail: renqiusheng1971@yahoo.com

W. Yu, MD

Department of Respiratory, Yinzhou People's Hospital, Ningbo University Medical College, Ningbo, Zhejiang, China

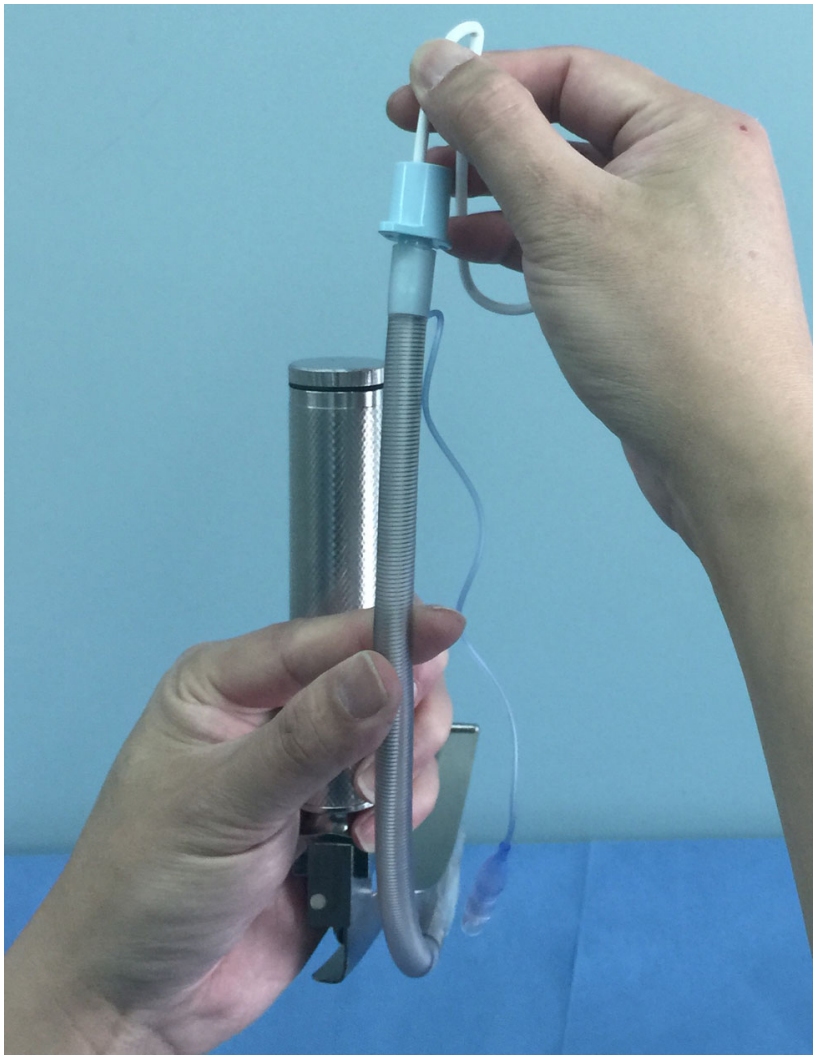

Figure One-person technique for advancing a styletted endotracheal tube (ETT) into the trachea when no assistant is available. After the ETT is advanced through the glottis, the thumb and forefingers of the left hand that is holding the laryngoscope are used to advance the ETT into the tracheal as the right hand withdraws the stylet

then grasps the stylet while the ETT is advanced into the trachea by the thumb and forefinger of the left hand (Figure). The right hand can then remove the stylet while the left hand continues to hold the ETT and laryngoscope. 
Finally, the laryngoscope is withdrawn, and the correct position of the ETT is confirmed.

This technique may be more challenging for an operator with relatively short fingers. We recommend attempting it a few times with an assistant available as a backup before making it routine practice in situations where no help is available.
Funding This work did not require any funding.

Conflicts of interest None declared.

Editorial responsibility This submission was handled by Dr. Hilary P. Grocott, Editor-in-Chief, Canadian Journal of Anesthesia. 